\title{
DINÂMICA IMOBILIÁRIA EM CIDADES MÉDIAS: a expansão dos empreendimentos horizontais em Montes Claros/MG
}

\author{
REAL ESTATE DYNAMIC IN MEDIUM-SIZED CITES: the \\ expansion of horizontal projects in Montes Claros/MG
}

\author{
Iara Soares de França \\ UNIMONTES \\ isfufu@yahoo.com.br \\ Maria Ivete Soares de Almeida \\ UNIMONTES \\ ivetegeo@yahoo.com.br \\ Ricardo dos Santos Oliveira \\ UNIMONTES \\ ricardoliveira.port@hotmail.com
}

\begin{abstract}
RESUMO
Este artigo analisa a produção do espaço urbano na cidade média de Montes Claros/MG após a década de 2000, a partir da expansão dos condomínios horizontais e dos loteamentos fechados. Destaca-se Montes Claros/MG no contexto das cidades médias brasileiras. Trata-se de uma cidade média que, dentre outras transformações, passa por uma nova dinâmica imobiliária, processo intensificado no final do século XX, representando uma transformação no contexto urbano em sua estrutura social, econômica, política e também cultural. Montes Claros vivencia uma fase crescente de novos padrões de consumo imobiliário, quer seja com a finalidade de moradia, negócios ou ambos. A expansão urbana dessa cidade média reflete o seu atual momento econômico, o que impacta os diversos setores da economia, principalmente o terciário.
\end{abstract}

Palavras-chave: cidades médias, produção do espaço urbano, condomínios horizontais, loteamentos fechados, Montes Claros/MG.

\begin{abstract}
This article analysis the production of urban space in Montes Claros/MG after the 2000's from the perspective of horizontal condominiums and closed allotments. This article shows Montes Claros in the context of Brazilian Medium Sized Cities. It is a medium sized city that, among other transformations, has been going through a real estate new dynamic intensified in the $20^{\text {th }}$ century, representing a transformation in its social, economic, political and cultural structures. Montes Claros has been undergoing a growing phase of new real estate consumption patterns related to housing, business or
\end{abstract}


both. The urban expansion of this medium sized city reflects its current economic momentum, which impacts the various economic sectors, especially the tertiary one.

Key Words: Medium Sized Cities; Production of Urban Space; Horizontal Condominiums; Closed Allotments; Montes Claros/MG.

\section{Introdução}

No Brasil o crescente processo de urbanização consolidado após a $2^{\mathrm{a}}$ metade do século XX provocou alterações importantes na dinâmica econômica, política e social do país com efeitos no espaço geográfico, destacando-se a reestruturação da Rede Urbana Brasileira. Os dados do recenseamento realizado pelo Instituto Brasileiro de Geografia e Estatística/IBGE mostram que em 2010, 84 \% da população residia em áreas urbanas. Isso representava, no mesmo ano, 165.898.169 pessoas vivendo nesses espaços. Estes números demonstram a alta taxa de urbanização em um país de grande contingente populacional que possui um total de 196.655.014 habitantes (Censo Demográfico do IBGE, 2010).

Nesse contexto, o fenômeno urbano no Brasil nas últimas décadas revelou um novo padrão de urbanização. Até meados da década de 1970 o processo de urbanização teve nas metrópoles nacionais a base quase que exclusiva de sua articulação e reprodução. Após esse momento com a desconcentração econômica e industrial metropolitana, configura-se a emergência das cidades médias como importantes espaços na economia do país.

Para Santos (1994, p.34) uma das características que marcam o atual fenômeno urbano no Brasil refere-se ao "aumento do número de cidades locais e sua força, assim como dos centros regionais, ao passo que as metrópoles regionais tendem a crescer relativamente mais que as próprias metrópoles do sudeste."

Conforme o Censo Demográfico do IBGE (2010) os municípios que protagonizaram, em conjunto, os mais expressivos crescimentos no período 2000-2012 foram aqueles com população entre 100 mil e 500 mil habitantes, revelando que o dinamismo populacional do Brasil continua seguindo novas rotas, particularmente rumo ao interior. 
Nesse sentido, este artigo analisa o processo de expansão urbana horizontal e as transformações socioespaciais que marcam o espaço urbano da cidade média de Montes Claros/MG, após a década de 2000'. Montes Claros é uma cidade dinâmica e isso se traduz na instalação de infraestruturas e equipamentos urbanos, aquecimento da economia e dos negócios, especialmente no setor imobiliário. Para a análise proposta, consideraram-se os aspectos determinantes para os novos padrões urbanos de moradias, negócios e consumo em Montes Claros e analisaram-se as ações e estratégias de agentes urbanos fundamentais: poder público e empreendedores imobiliários envolvidos no processo da expansão urbana desta cidade média. As transformações socioespaciais ocorridas do ponto de vista da estruturação do espaço urbano e seus impactos na produção habitacional e econômica ${ }^{\text {ii }}$ refletem na atual configuração dessa cidade média norte mineira.

A metodologia utilizada neste estudo consistiu em análise bibliográfica de autores que discorrem sobre as temáticas: produção do espaço urbano, urbanização brasileira, cidades médias ${ }^{\mathrm{iii}}$, expansão urbana, condomínios horizontais e loteamentos fechados. Foram realizadas no ano de 2012 entrevistas com representantes do segmento imobiliário, a fim de conhecer sua visão sobre o atual momento imobiliário de Montes Claros. Analisaram-se fontes secundárias como as Leis Federais que normatizam os loteamentos fechados: Lei № 4.591 de 16 de Dezembro de 1964, a Lei Municipal No 3.720 de 09 de Maio de $2007^{\text {iv }}$, dentre outras. Outras fontes utilizadas para a análise proposta referem-se a registro iconográfico e pesquisa sobre a evolução do número de empreendimentos horizontais nos $1^{\mathrm{o}}$ e $2^{\circ}$ Cartórios de Registro de Imóveis, Corpo de Bombeiros e Construtoras Civis de Montes Claros. Os resultados foram analisados à luz da teoria e representados sob a forma de mapas e figuras.

\section{Produção do espaço urbano em Montes Claros/MG: a expansão urbana horizontal}

No processo de produção do espaço urbano contemporâneo verifica-se um novo padrão de urbanização resultante de profundas transformações socioespaciais que ocasionam novos usos e ocupação do solo urbano e, com isso, novas formas urbanas, por exemplo, os empreendimentos horizontais e os loteamentos fechados. 
Sobre os termos loteamentos, loteamentos fechados e condomínios horizontais, Guimarães (2012, p.7) esclarece

A diferença mais chamativa entre os "condomínios" horizontais, loteamentos fechados e os loteamentos é exatamente essa: nos condôminos horizontais e nos loteamentos fechados existe uma parte de uso comum que pertence ao condomínio, enquanto que nos loteamentos propriamente ditos, o sistema viário, arruamento, os equipamentos urbanos e também os comunitários, assim como as vias, praças, espaços livres e áreas destinadas a edifícios públicos, constantes no projeto e no memorial descritivo, serão transferidos à municipalidade, desde a data de registro do loteamento, passando desde aquele momento integrar aquilo que se reconhece como patrimônio afetado à finalidade pública.

Verifica-se a produção do espaço urbano como mercadoria, processo relacionado à produção capitalista que associa interesses de agentes imobiliários, empresas, Estado e grupos sociais diversos. O Estado é o grande responsável por beneficiar a construção de empreendimentos que favoreçam os grandes promotores imobiliários, sendo ele também o dono de inúmeros solos (CORRÊA, 1989).

De acordo com Silva (2007) a expansão territorial das cidades é guiada por lógicas onde "a produção e reprodução do espaço urbano contemporâneos é produto, condição e meio das relações capitalistas nela existentes".

Portanto, o capital privado e o poder público são produtores do espaço urbano contemporâneo, sendo que esse espaço se reestrutura quando a cidade passa por diferentes momentos econômicos, políticos, sociais e culturais. Esses diferentes momentos se agregam aos diversos fragmentos do território urbano no decorrer do tempo, refletindo um mosaico urbano como resultado de sua reestruturação (SPÓSITO, 2007).

Sobarzo (2007, p. 203) comenta essa nova dinâmica urbana apontando que esses "novos produtos" alimentam, reforçam e respondem ao desejo de um segmento da população de maior poder aquisitivo de se diferenciar, dispondo na cidade de seus espaços próprios. Por outro lado, a maioria da população, ou seja, a de menor poder aquisitivo ocupa espaços longínquos com péssimas condições de infraestrutura. Dessa forma, essa diferenciação social reforça a segregação socioespacial.

Os estudos sobre os empreendimentos horizontais em cidades médias são recentes, datam, sobretudo, do final do século XX e início do século atual. Destes podem-se destacar os condomínios horizontais fechados nas cidades médias paulistas de 
São José do Rio Preto, Presidente Prudente e Sorocaba (SPÓSITO, 2007; SOBARZO, 2007; 2001) e os estudos sobre os loteamentos fechados em Londrina no Paraná (SILVA, 2007).

A expansão dos condomínios horizontais fechados e dos loteamentos fechados é um fenômeno em crescimento em Montes Claros/MG, conjuntura semelhante ao que ocorre em outras cidades médias brasileiras. Nesta cidade a implantação desses empreendimentos apresentou um crescimento considerável após a década de 1990.

Nessa perspectiva, torna-se necessário avaliar os impactos que esses novos padrões de moradia e consumo provocam no espaço urbano dessa cidade média aliados à ação de produção e reprodução de agentes urbanos, tais como o Estado e promotores imobiliários.

Sendo assim, a produção do espaço urbano de Montes Claros a partir dos condomínios horizontais e dos loteamentos fechados suscita algumas questões: Como os empreendimentos urbanos horizontais interferem na produção do espaço urbano de Montes Claros? Qual é a participação do poder público e de outros atores na expansão urbana? As respostas para estas questões advêm da necessidade de compreender a cidade e, por conseguinte, a sociedade.

Essas novas formas urbanas, assim como outros elementos urbanos ou geográficos, carecem de pesquisas constantes, visto ser um processo que está inscrito no espaço, que é constantemente transformado, modificado ou metamorfoseado, mas também no tempo. O processo de produção e reprodução do espaço é muito dinâmico (TOWS, MENDES, 2011, p.18).

\section{Os condomínios horizontais e os loteamentos fechados em Montes Claros/MG}

Montes Claros, cidade média localizada no Norte de Minas Gerais (Mapa 1), apresenta uma população total de 361.915 mil habitantes (IBGE, 2010). O município é uma das maiores economias mineiras representando o $11^{\circ}$ lugar no ranking municipal de composição do PIB estadual, em 2010. De acordo com o IBGE Cidades (2013) ${ }^{\mathrm{v}}$, no ano de 2010 Montes Claros/MG apresentou PIB no valor de $\quad \mathrm{R} \$ 4,5$ bilhões. Considerando o PIB por setores econômicos, no ano de 2010, destaca-se a participação do setor de 
serviços com 74\%, enquanto os setores industrial e agropecuário responderam, respectivamente, por 24\% e 3\% do PIB municipal. (Ano 2010, Valores: 1Mil R\$, Fonte: IBGE Cidades, 2013).

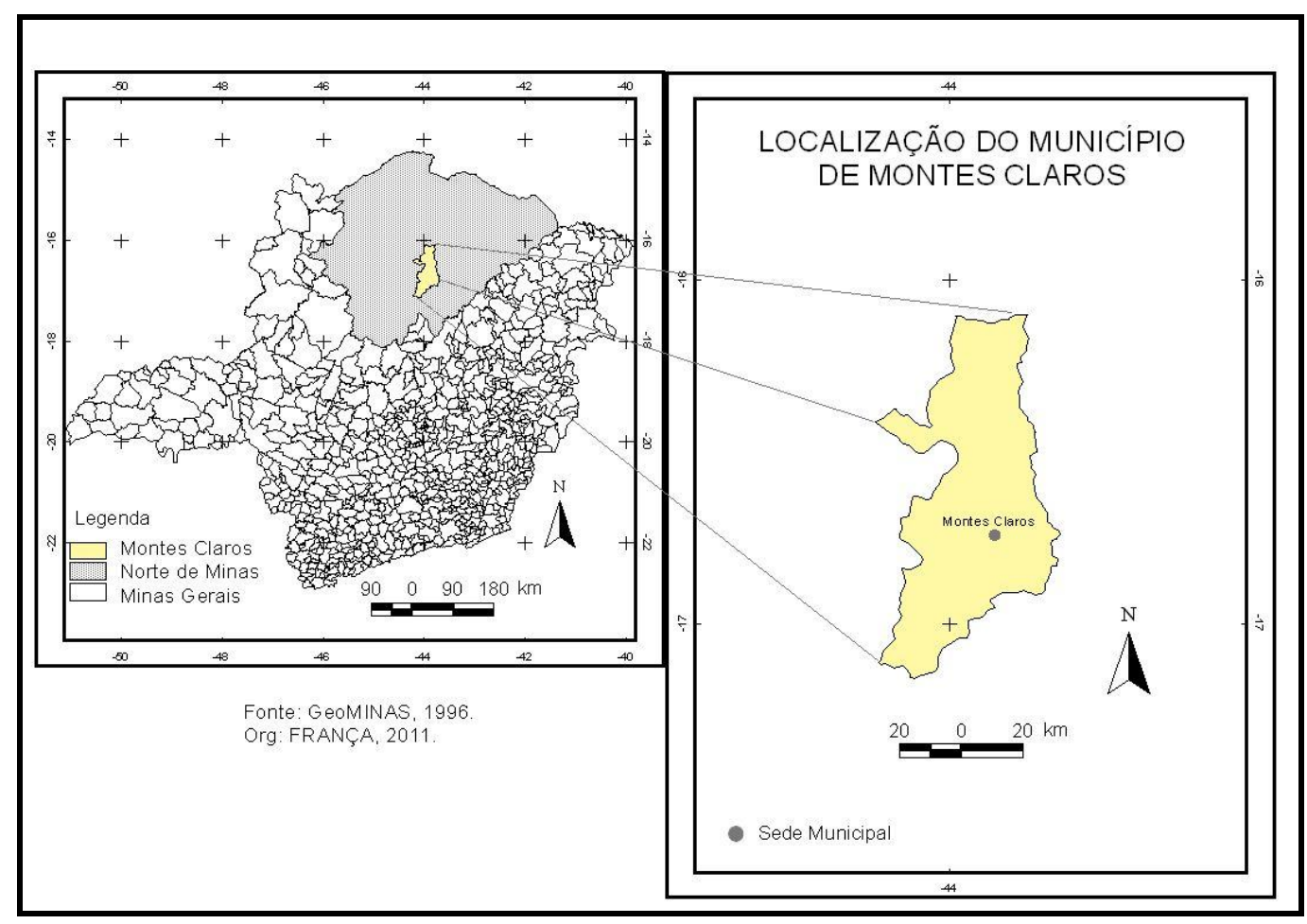

Mapa 1 - Localização do município de Montes Claros/MG

Essa cidade média exerce relevante papel regional, o seu dinamismo tem atraído significativas atividades terciárias e instalações industriais contribuindo assim para o seu desenvolvimento. Com isso, Montes Claros assume uma posição de centralidade intra e interurbana, destacando-se como o núcleo urbano mais dinâmico da região Norte de Minas.

Montes Claros é apontada por diversos estudos, tais como: Andrade e Lodder, 1979; Amorim Filho, Bueno e Abreu, 1982; Pereira e Lemos, 2004; Pereira, 2007; França, 2007, 2012, entre outros, como uma cidade média ${ }^{\mathrm{vi}}$ na região Norte de Minas.

É necessário estabelecer a diferença entre as noções cidade média e cidade de porte médio. O tamanho demográfico é suficiente para dotar a noção de cidade de porte médio. Já as cidades médias se destacam pelos papéis por elas desempenhados no 
âmbito econômico, regional e também a articulação entre os níveis inter-urbano e intraurbano. Outros critérios são utilizados para classificar as cidades médias, a saber: características funcionais, papel de ligação entre centros locais e globais, grau de urbanização, centralidade e qualidade de vida urbana. (WHITACKER, 2007, CASTELLO BRANCO, 2006, SPÓSITO, 2001).

Um dos aspectos observados nas cidades médias brasileiras na atualidade referese ao processo de expansão urbana relacionado ao surgimento de novas moradias, novas formas de consumo e negócios por meio dos empreendimentos horizontais.

O setor imobiliário de Montes Claros vive uma nova valorização e dinâmica resultantes de fortes transformações socioespaciais e econômicas. Os condomínios horizontais e os loteamentos fechados são formas que traduzem a nova realidade dessa cidade média. Nessa perspectiva, foram realizadas entrevistas com os representantes de várias construtoras imobiliárias que atuam em Montes Claros no segmento imobiliário desde a década de 1990 para avaliar a sua opinião sobre o processo de expansão urbana por ela vivenciado. A figura 1 procura sintetizar a visão dos empreendedores. 
Há uma explosáo imobiliária no Brasil inteiro, mas em Montes Claros isso está sob controle. Observou que antes quando o mercado financeiro estava bom e o mercado imobiliário estava ruim, hoje inverteu; há uma grande valorizaçào dos lotes e as pessoas estăo investindo,tende muito em imóveis.

Com a situaçáo econômica estável do pais, facilitou o desenvolvimento da construçăo civil nâo só aqui, mas no Brasil todo, mas particularmente em Montes Claros, é devido ao seu crescimento assim bastante significativo nesse periodo, nesses últimos anos.

É indústria, é comércio e a própria construçăo, é melhoria da renda a melhoria da quantidade de oferta de trabalho, o mercado de trabalho melhorou. Montes Claros é uma cidade pólo comercial, universitário e por ai vai, uma coisa puxa a outra e nós damos graças a Deus.
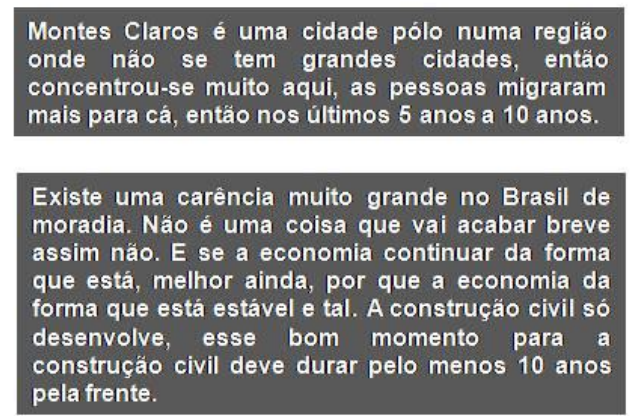

Tem muitas pessoas construindo, e com isso logo o mercado vai ficar saturado. Tem muita gente construindo, engenheiros construindo, dentistas construindo.

Figura 1: O momento imobiliário em Montes Claros/MG: a visão dos empreendedores imobiliários.

Fonte: Pesquisa Direta, 2012.

Org.: FRANÇA, Iara Soares de.

A expansão do setor imobiliário em Montes Claros tem atraído capitais e investidores de vários locais do país, há empresas imobiliárias de São Paulo, Belo Horizonte e do Pará, dentre outras localidades. Essas empresas exercem várias funções, constroem, locam, incorporam, gestam e vendem. A atuação dos agentes por meios das empresas tem alterado a dinâmica imobiliária de Montes Claros. As empresas imobiliárias selecionam áreas e as dotam de capital provocando o uso privado do solo urbano em detrimento da sua função social. É na zona sul de Montes Claros que se nota a intensidade dos investimentos financeiros das construtoras, nas zonas leste e norte da cidade os investimentos e as ocupações são bastante diferenciadas, pois se direcionam para as classes de baixo poder aquisitivo.

A partir de levantamentos realizados em Cartórios Civis de Montes Claros, Corpo de Bombeiros e Construtoras, verificou-se que a expansão dos condomínios horizontais e dos loteamentos fechados em Montes Claros se deu a partir da década de 
1990. Em 1975 foi construído o loteamento fechado Panorama, localizado na zona oeste de Montes Claros. A partir desse ano, a implantação dos empreendimentos horizontais em Montes Claros foi inexpressiva até o ano 2000, quando o processo ganha intensidade. Dois condomínios foram construídos em 2000; um em 2004, um 2006 e um em 2007. Nos anos de 2009 e 2010 foram construídos, dois condomínios, num total de quatro. No ano de 2011 acelera-se o ritmo com a implantação de oito empreendimentos horizontais. No ano de 2012 cinco condomínios foram construídos e em 2013 um condomínio foi construído. Montes Claros possui atualmente um total de 24 desses empreendimentos horizontais, sendo que $96 \%$ foram construídos a partir dos anos 2000. (Pesquisa Direta, 2013).

A distribuição espacial desses empreendimentos no espaço urbano de Montes Claros se configura-se a partir das seguintes características: segurança, amenidades ambientais, infraestrutura, exclusividade social. Neste aspecto, a zona oeste de Montes Claros é a área de maior concentração desses empreendimentos, notadamente no Bairro Ibituruna. Esta área de Montes Claros apresenta características bastante peculiares que a difere de outras, tais como boa infraestrutura, relativa proximidade com a área central, a presença da Serra da Sapucaia que lhe confere amenidades ambientais e paisagismo. Ademais, esta área da cidade é ocupada por uma população de alta renda. (Fotos 1, 2, 3 e 4).

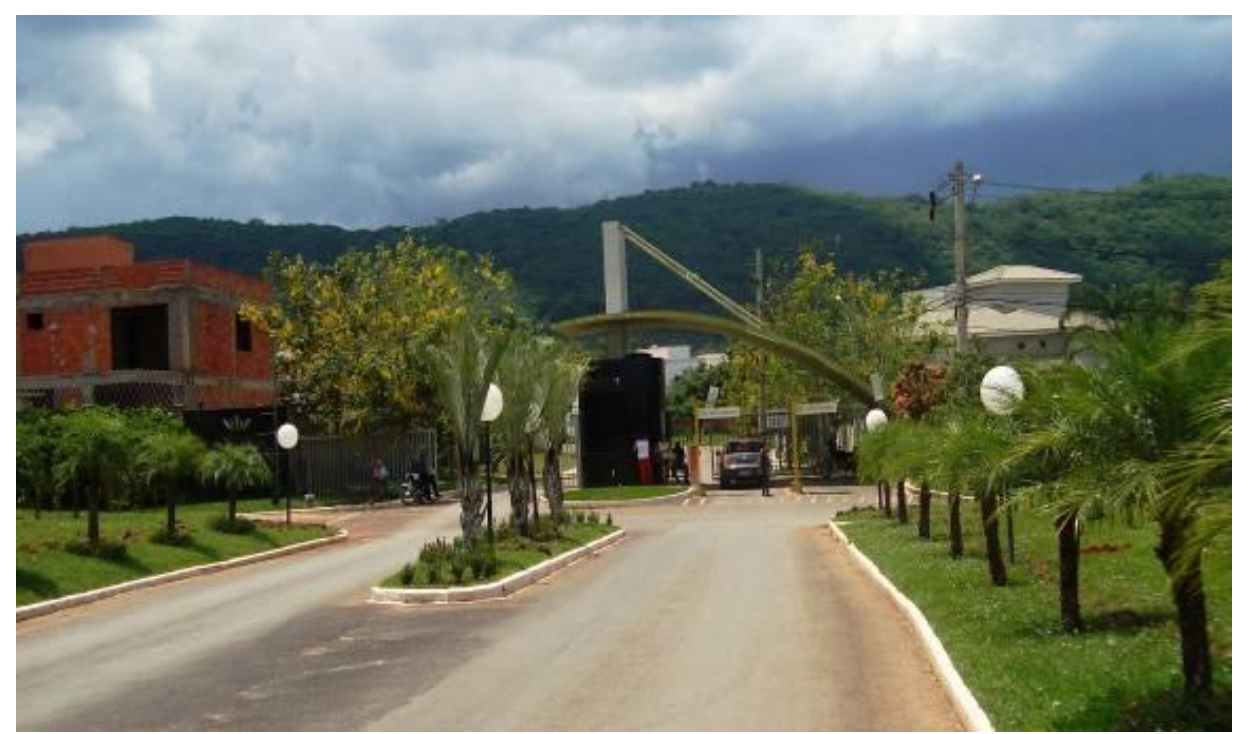

Foto 1: Condomínio Portal das Acácias, Zona Oeste.

Geo UERJ. Rio de Janeiro - Ano 16, nº. 25, v. 1, $1^{\circ}$ semestre de 2014, pp.19-38

ISSN: 1415-7543 E-ISSN: 1981-9021

http://www.e-publicacoes.uerj.br/index.php/geouerj 
Autor: OLIVEIRA. R. S. 2012.

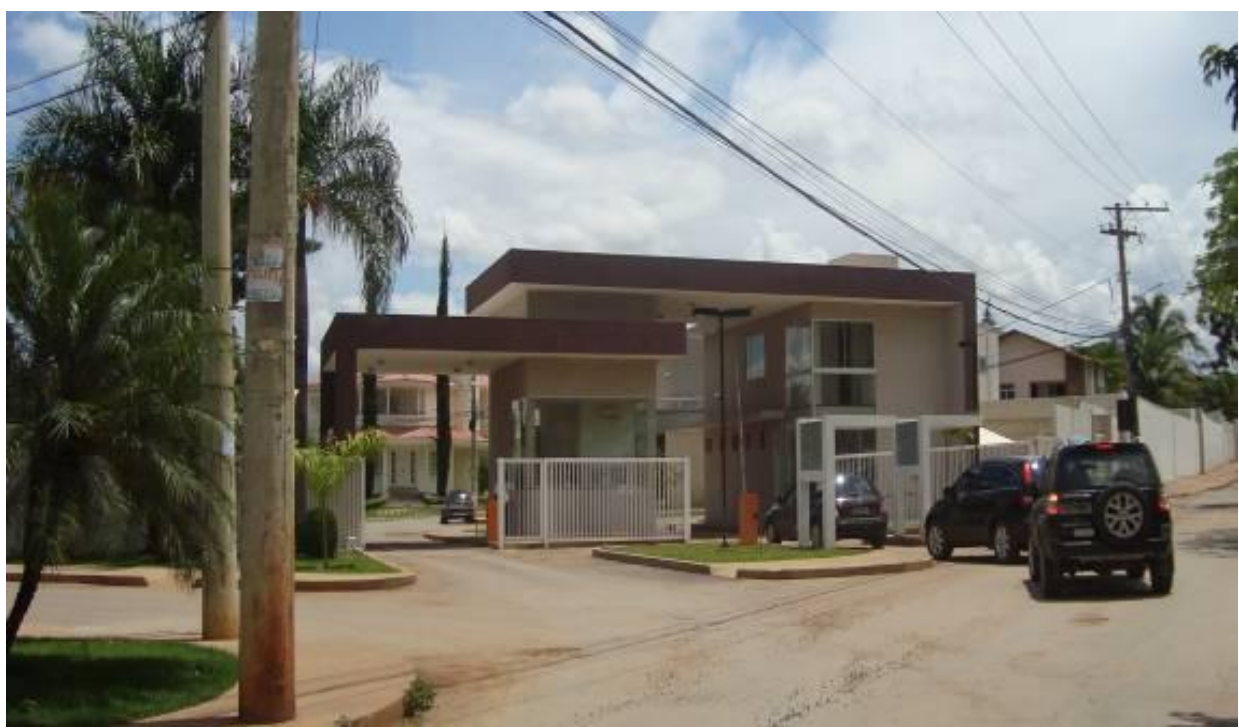

Foto 2: Condomínio Portal das Aroeiras, Zona Oeste.

Autor: OLIVEIRA, R. S. 2012.

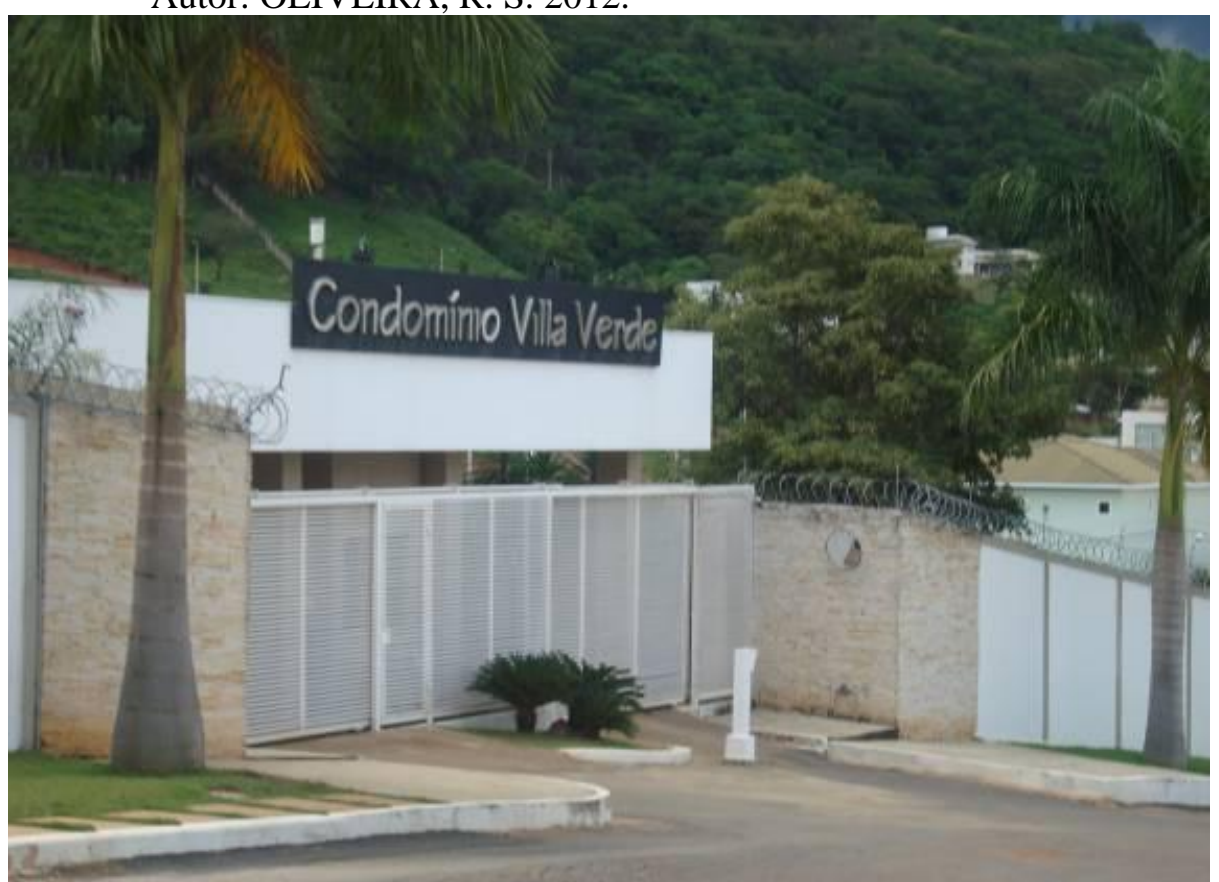

Foto 3: Condomínio Villa Verde, Zona Oeste.

Autor: OLIVEIRA. R. S. 2012. 


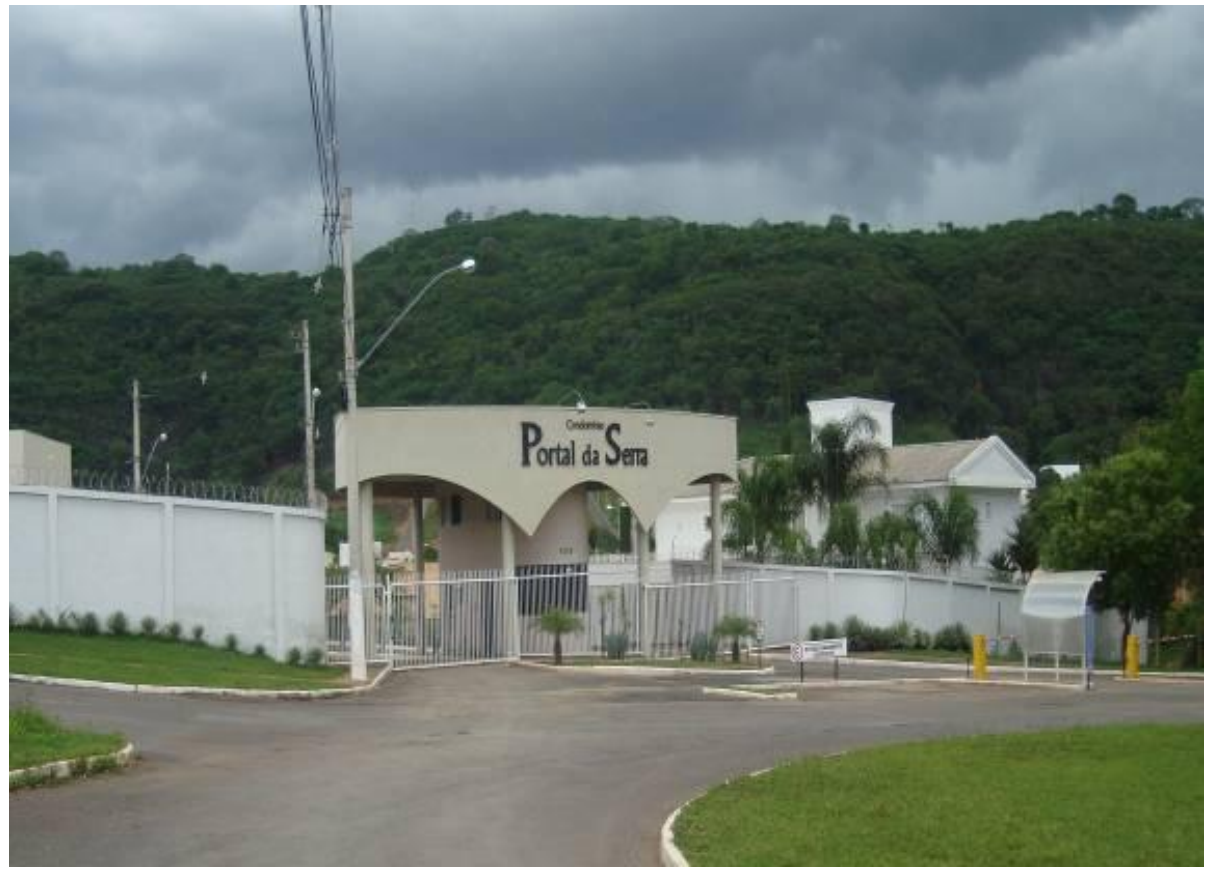

Foto 4: Condomínio Portal da Serra. Autor: OLIVEIRA, R. S. 2012.

Embora a zona oeste de Montes Claros possua a maior concentração dos condomínios horizontais e dos loteamentos fechados, outras áreas da cidade, especialmente as zonas leste e norte, têm atraído também a instalação desses empreendimentos promovendo uma nova configuração da periferia urbana.

As fotos 5 e 6 mostram condomínios localizados, respectivamente, na Zona Leste e Norte de Montes Claros. 


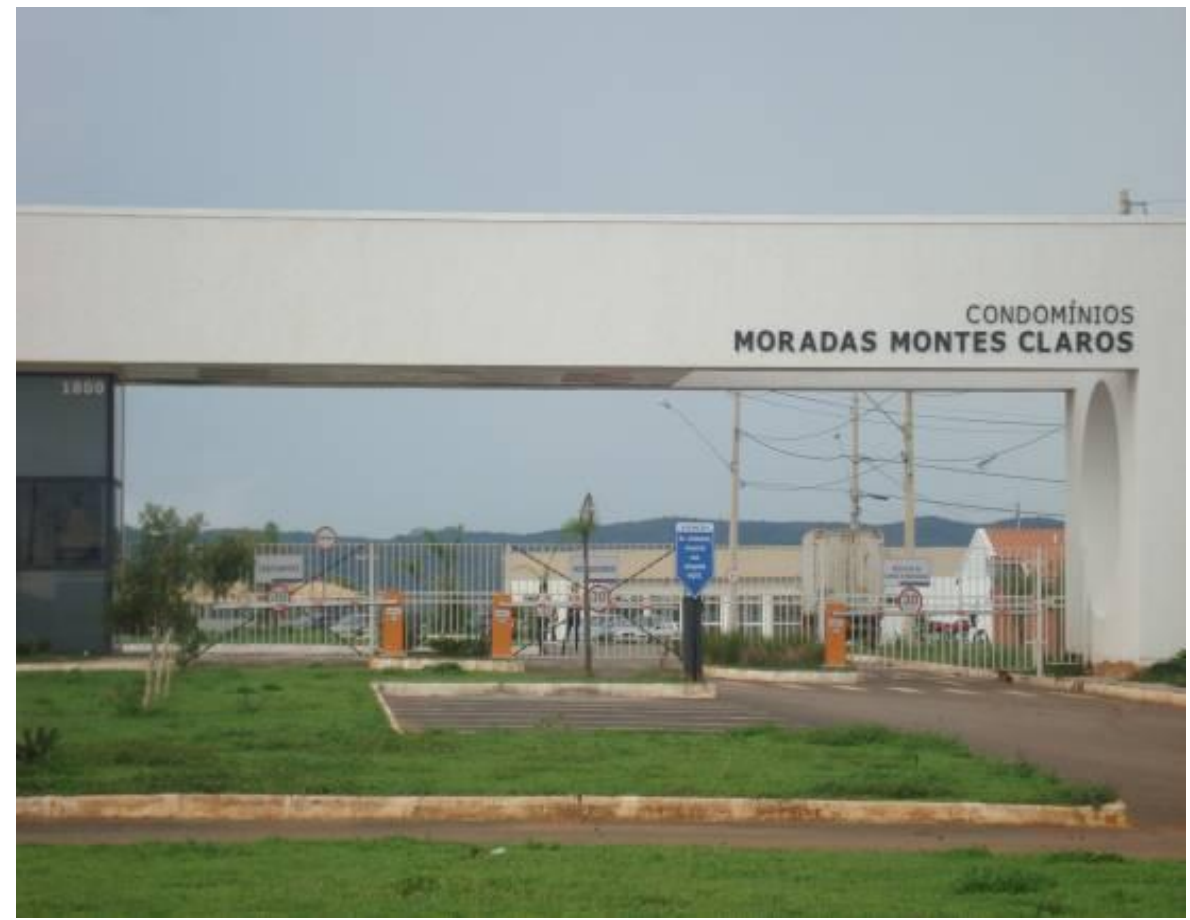

Foto 5: Condomínio Moradas Montes Claros, Zona Leste. Autor: OLIVEIRA, R. S. 2012.

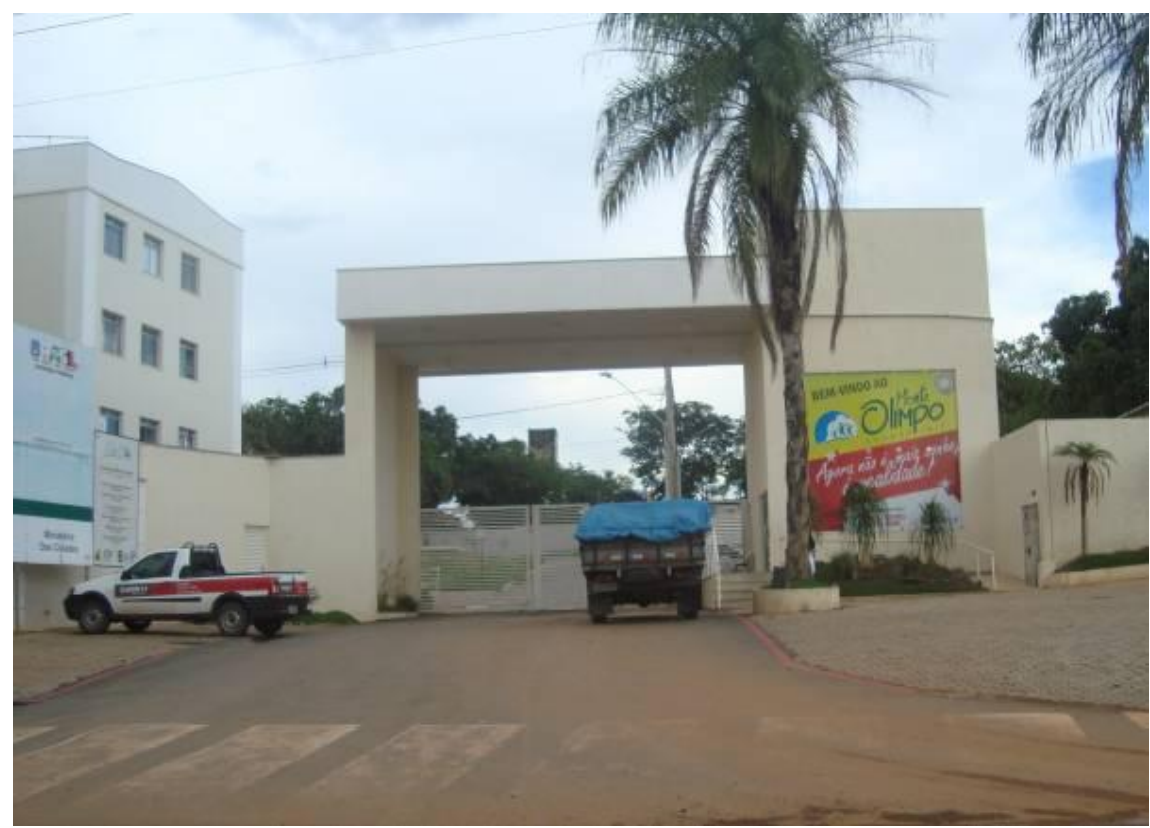

Foto 6: Condomínio Monte Olimpo, Zona Norte. Autor: OLIVEIRA. R. S. 2012.

Observa-se a diferença no padrão desses empreendimentos localizados na zona oeste com aqueles localizados nas zonas leste e norte onde reside, sobretudo, população 
de menor renda, sendo que alguns desses empreendimentos são financiados pelo Programa do Governo Federal Minha Casa Minha Vida. Nesse sentido, fica evidente que o aquecimento do setor imobiliário em Montes Claros vincula-se a uma nova dinâmica do referido setor por meio de novos investimentos e negócios, ao aumento do poder aquisitivo da população de várias classes econômicas e à expansão do acesso ao crédito imobiliário, visando à diminuição do déficit de moradias para as populações de baixa renda.

A distribuição espacial heterogênea dos condomínios horizontais e dos loteamentos fechados em Montes Claros imprime uma nova morfologia urbana nessa cidade média. Negativamente, o espraiamento desses empreendimentos em Montes Claros contribui para a prática da especulação imobiliária e o Estado legitima a ação dos agentes imobiliários por meio do aparato legislativo.

O poder público municipal é um importante agente no processo de produção e reprodução do espaço urbano. Através do aparato legal ele atua como legislador e tributador. Mas o Estado é também agente financiador, empresário e conciliador nos conflitos que envolvem os demais agentes produtores do espaço urbano. Em Montes Claros, a construção dos empreendimentos horizontais tem sido motivo de conflitos entre poder público municipal, sociedade civil e Ministério Público.

$\mathrm{O}$ forte interesse em beneficiar as empresas do ramo imobiliário civil, quer seja de vinculadas aos empreendimentos urbanos horizontais ou verticais, por parte do poder público municipal tem gerado a produção e reprodução do espaço urbano em desacordo com as leis específicas. A visão de um ex-representante do poder público municipal, então secretário de planejamento urbano, em entrevista e sistematizada na figura 2 , corrobora tal assertiva. 


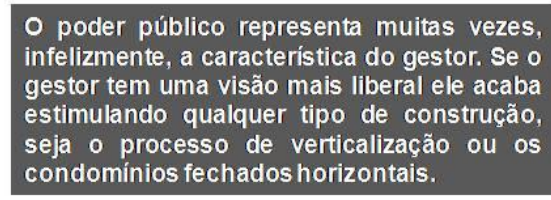

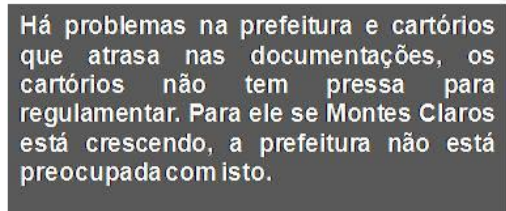

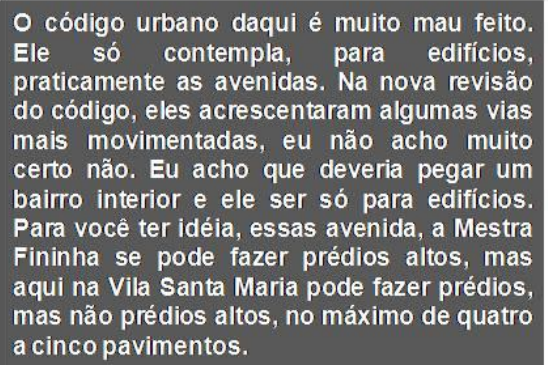

Figura 2: A ação do poder público e os agentes imobiliários em Montes Claros/MG. Fonte: Pesquisa Direta, 2012.

Org.: FRANÇA, Iara Soares de.

Ainda sobre os aspectos jurídicos concernente à instalação dos condomínios horizontais em relação ao processo de loteamento, tanto convencional como fechado, a legislação municipal Lei 3.720, de 9 de Maio de 2007, diz no Art. 1:

Parágrafo único - As áreas externas ao perímetro urbano não poderão ser loteadas para fins urbanos, exceto quando houver interesse público relevante, caso em que o Município deverá ampliar o perímetro urbano através de Lei específica, ouvido o INCRA - Instituto acional de Colonização e Reforma Agrária.

Atendendo aos interesses do capital imobiliário, e reforçando a parceria público privada na produção de espaços urbanos ligados à lógica capitalista de produção, o poder público municipal propôs a alteração do perímetro urbano para englobar novos loteamentos na zona oeste de Montes Claros. Em 2011 a prefeitura propôs o Projeto de Lei de Ampliação do Perímetro Urbano de Montes Claros, alterando o perímetro urbano estabelecido pela Lei Municipal 4.198 de 2009. Objetivava com isso, resolver a questão da legalidade, no entanto o projeto foi embargado pelo Ministério Público. 
Conforme Maricato (2002), isso mostra que o aparato regulatório exagerado das leis de uso e ocupação do solo convive com radical flexibilidade. A autora expressa bem esse jogo entre público e privado ao afirmar que a ineficácia dessa legislação é, de fato, apenas exercício arbitrário do poder, além de favorecer pequenos interesses corporativos. A ocupação ilegal da terra urbana não só é permitida como é parte do modelo de desenvolvimento urbano no Brasil, ao lado da detalhada legislação urbanística.

Outro aspecto dos loteamentos que começa a ser verificado nas cidades médias são os condomínios fechados rurais no entorno do perímetro urbano. Esses loteamentos chamam a atenção por oferecerem qualidade ambiental, áreas verdes e por serem distantes da área central da cidade. Compreendendo a área de ampliação do perímetro urbano de Montes Claros a partir da lei aqui tratada verifica-se a concessão dessas construções. Tais condomínios, por exemplo o Grand Royalle Pirâmide ${ }^{\text {vii }}$ outrora pertencente a área rural do município, com a alteração do perímetro urbano, foi incorporado a área urbana.

Diante dessa problemática envolvendo o aspecto legal dos loteamentos fechados é importante analisar suas implicações no espaço urbano. De acordo Silva (2007, p. 226) os "loteamentos fechados possuem uma lógica que evidencia uma plus de segregação, pois se tem, ainda, uma prática de apropriação privada de terrenos públicos".

Geralmente esses empreendimentos segregam por serem construídos em áreas valorizadas da cidade. De acordo Botelho (2007, p. 62):

É nas áreas mais valorizadas da cidade, onde se concentra a infra-estrutura,
que a lei urbanística é aplicada em sua integralidade, beneficiando o mercado
imobiliário destinado às classes médias e altas, e isso resulta a segregação
socioespacial. Já nas áreas pobres a lei urbanística não é aplicada.

Em Montes Claros verificou-se a instalação de inúmeros loteamentos, sobretudo, em áreas urbanas dotadas de boa infraestrutura e amenidades ambientais. Na produção do espaço urbano dessa cidade média vários processos espaciais e culturais, dentre outros, encontram-se em curso, onde se manifestam parcerias público-privada além de conflitos de legalidade e ilegalidade no solo urbano. A expansão urbana horizontal em Montes Claros revela ainda, uma transformação cultural no que se refere as novas 
formas de morar em cidades médias mediadas pela idéia de segurança, qualidade de vida, além de status social. As dimensões espacial e cultural, dentre outras, apontam elementos para novas pesquisas urbanas nessa cidade média.

\section{Considerações Finais}

O crescimento demográfico acelerado após a década de 1970 desencadeou a expansão urbana da cidade média de Montes Claros/MG, paralelamente às transformações econômicas no âmbito intra e interurbano. Tais mudanças tiveram como suporte a crescente demanda de consumo da população em consonância com a lógica capitalista concentradora e desigual.

Nesta cidade média destaca-se, dentre outros processos, o crescimento do setor imobiliário onde os espaços urbanos periféricos vêm sendo redefinidos por novas formas de moradias e de consumo.

Nesse sentido, este artigo analisou o surgimento dos loteamentos e condomínios fechados após a década de 2000. Em um total de 24 empreendimentos horizontais construídos, verificou-se que a maior parte estão localizados na zona oeste da cidade, área de amenidade ambiental e boa infraestrutura urbana ocupada, sobretudo por uma população de alta renda. Todavia, a expansão urbana horizontal de Montes Claros não se restringe a essa área da cidade. Nas zonas leste e norte muitos condomínios horizontais e loteamentos fechados construídos e em construção atendem a demanda de moradia de populações de menor poder aquisitivo. Esses empreendimentos caracterizam-se, predominantemente, por um padrão de ocupação da população de menor renda, inclusive inserindo os recursos do Programa Minha Casa Minha Vida do Governo Federal.

Em ambos os casos, percebeu-se a forte atuação do poder público e empreendedores imobiliários, por exemplo, o aumento expressivo do número de construtoras instaladas em Montes Claros e de diversas localidades como SP, BH, PA, entre outras, que atuam no segmento civil. 
A instalação dos empreendimentos horizontais nesta cidade média resulta em vários conflitos e na segregação socioespacial, na luta pelo direito a cidade, no não cumprimento de normas de uso e ocupação do solo urbano ditado pela acumulação de capital e especulação imobiliária.

Esses elementos demonstram que o crescimento territorial das cidades faz parte de sua própria lógica de expansão urbana que cresce horizontalmente a partir da formação de novos loteamentos em áreas consideradas periféricas espacialmente, mas também em termos de infraestruturas urbanas.

Isso denota uma nova conjuntura econômica, política, demográfica e cultural vivenciada por essa cidade média, demonstrando uma dinâmica urbana que permeia a implantação desses empreendimentos. Trata-se de um complexo processo, envolvendo agentes econômicos e políticos, reflexo da realidade urbana brasileira e montesclarense.

\footnotetext{
${ }^{\mathrm{i}}$ Este artigo integra os resultados da pesquisa Novas Formas de Consumo Residencial e Comercial e a Dinâmica Espacial da Cidade Média de Montes Claros: O Processo de Verticalização e os Condomínios Horizontais após a Década de 1990 desenvolvida pelos autores na Universidade Estadual de Montes Claros/UNIMONTES. Aprovação: RESOLUÇÃO No 034 - CEPEx/2012.

ii A Revista Veja (Edição 2241, Ano 44, N.44, 2 de Novembro de 2011, p.146-181), na reportagem "Especial Cidades - As campeãs de riqueza e de bem estar", destacou Montes Claros da seguinte forma: "A cidade tem fábricas de grande porte, como a da Nestlé e a da Novo Nordisk. É referência em educação e comércio para mais de 80 municípios ao seu redor, incluindo alguns do sul da Bahia. Conta com três faculdades de medicina e cinco hospitais, que atraem a população das redondezas. Nos últimos quatro anos inaugurou três shoppings. (Revista Veja, Nov. 2011, p.179). O Jornal Folha de São Paulo retratou o dinamismo econômico, demográfico e infraestrutural das cidades médias brasileiras: Jornal Folha de São Paulo - Reportagem "Aumenta o peso das cidades médias no consumo nacional", Domingo 21 de Março de 2010; Jornal Folha de São Paulo - Reportagem "Cidades de Médio Porte são as que mais crescem, aponta IBGE", Sábado, $1^{\circ}$. de Setembro de 2012.). Recentemente o Jornal Folha de São Paulo (Domingo, 03 de Fevereiro de 2013), por meio da Série de Reportagens "O Brasil que mais cresce" destacou o crescimento econômico e os desafios na urbanização problemática, colocando a necessidade de projetos de revitalização para Montes Claros.

iii Pesquisadores como Amorim Filho (1976); Andrade e Lodder (1979); Andrade e Serra (2001); Soares (1999, 2005); Spósito (2001), entre outros, tem direcionado seus estudos na investigação das cidades médias, a fim de compreendê-las no âmbito da geografia urbana.

${ }^{\text {iv }}$ A instituição de sistema de condomínios é regulamentada pela Lei Federal no 4.591 , de 16 de Dezembro de 1964, onde diz no Art. $7^{\circ}$ o condomínio por unidades autônomas instituir-se-á por ato entre vivos ou por testamento, com inscrição obrigatória no Registro de Imóvel, dele constando; a individualização de cada unidade, sua identificação e discriminação, bem como a fração ideal sobre o terreno e partes comuns, atribuída a cada unidade, dispensando-se a descrição interna da unidade.

${ }^{v}$ Disponível em http:॥www.ibgecidades.gov.br

${ }^{v i}$ Montes Claros foi a única cidade do Norte de Minas incluída no Programa de Cidades de Porte Médio, parte integrante da política pública definida pelo II Plano Nacional de Desenvolvimento na década de 1970. (FRANÇA, 2007).

vii Anteriormente na área desse condomínio funcionava o Haras Pirâmide.
} 


\section{REFERÊNCIAS}

AMORIM FILHO, Oswaldo Bueno. BUENO, Maria Elisabeth Taitson e ABREU, João Francisco. Cidades de porte médio e o programa de ações sócioeducativo-culturais para as populações carentes do meio urbano em Minas Gerais. Boletim de Geografia Teorética, Rio Claro-SP, v.2,n. 23-24,33-46,1982.

AMORIM FILHO, Oswaldo Bueno. Esquema metodológico para o estudo das cidades médias. In: ENCONTRO NACIONAL DE GEOGRÁFOS. Resumo de comunicações e guias de excursões. Belo Horizonte: AGB, 1976, p. 6-15.

ANDRADE, Thompson Andrade; SERRA, Ricardo Valente.; (Org.). Cidades médias brasileiras. Rio de Janeiro: IPEA, 2001.

ANDRADE, Thompson Andrade, LODDER, Celsius Antônio. Sistema urbano e cidades médias no Brasil. IPEA. Rio de Janeiro: IPEA/INPES. 1979.

BOTELHO, Adriano. A Produção do Espaço Urbano e da Moradia através das práticas do setor imobiliário: três casos paulistanos. Cidades, v.4, n. 6, 2007, p. 11-43

CASTELO BRANCO, M. L. Cidades médias no Brasil. In: SPÓSITO, E. S.; SPÓSITO, M. E. B.; SOBARZO, O. (org.). Cidades médias: produção do espaço urbano e regional. São Paulo/SP: Expressão Popular, 2006. 375p. p. 245-277.

CORRÊA, Roberto Lobato. O espaço urbano. São Paulo: Ática, 1989.

FRANÇA, Iara Soares de. Aglomeração urbana descontínua de Montes Claros/MG: novas configurações socioespaciais. 2012. Tese (Doutorado em Geografia) - Instituto de Geografia, Universidade Federal de Uberlândia, Uberlândia: UFU, 2012. $393 f$.

FRANÇA, Iara Soares. A cidade Média e suas centralidades: o exemplo de Montes Claros no Norte de Minas Gerais. 204 f. 2007. Dissertação (Mestrado em Geografia) - Instituto de Geografia, Universidade Federal de Uberlândia, Uberlândia, 2007.

GUIMARÃES, Hilário Espirito Santo. "Condomínios" Atípicos. A Privatização e a Feudalização dos espaços Públicos Disponível em: http://www.conteudojuridico.com.br/?artigos\&ver=1055.31503. Acesso em: 05/09/2012.

INSTITUTO BRASILEIRO DE GEOGRAFIA E ESTATÍSTICA/IBGE. Censo Demográfico, 2010. Disponível em < http://www.ibge.gov.br htm/>.

LEI $\mathrm{N}^{\circ}$ 4.591, DE 16 DE DEZEMBRO DE 1964.Disponivel em: http://www.planalto.gov.br/ccivil_03/leis/L4591.htm. Acesso em 10/04/2012.

MARICATO, Hermínia. As idéias fora do lugar e o lugar fora das idéias, planejamento urbano no Brasil. In: ARANTES, O; VINER, C. MARICATO, E. A cidade do pensamento único, desmanchando consensos. Petrópolis - RJ: Vozes. $3^{\circ}$ Ed. 2002. 192 p. 
PEREIRA, Anete Marília. Cidade média e região e o significado de Montes Claros no Norte de Minas Gerais. 347f. 2007. Tese (Doutorado em Geografia)-Instituto de Geografia, Universidade Federal de Uberlândia, Uberlândia, 2007.

PEREIRA, Fabiano Maia; LEMOS, Mauro Borges. Cidades médias uma visão nacional e regional. XI Seminário sobre economia mineira. Diamantina, 24 a 27 de agosto de 2004. Anais. Disponível em http://www.cedeplar.ufmg.br.

PREFEITURA MUNICIPAL DE MONTES CLAROS. Lei No 4.198, DE 23 DE DEZEMBRO DE 2009. Dispõe sobre o uso e ocupação do solo no município de Montes Claros e da outras providencias. Disponível em: http://www.montesclaros.mg.gov.br/publica_legais/leis_pdf/leis2009/dez-09/leis\%204198-09.pdf. Acesso em: 14/06/2013.

PREFEITURA MUNICIPAL DE MONTES CLAROS. LEI No 3.720, DE 09 DE MAIO DE 2007. Dispõe sobre o parcelamento do solo urbano e loteamentos fechados no município de Montes Claros. Disponível em: http://www.montesclaros.mg.gov.br/publica_legais/leis_pdf/leis-2007/mai-07/lei-3720-07parcelamento-do-solo-urbano.pdf. 14/06/2013.

SANTOS, Milton. A urbanização Brasileira. São Paulo: HUCITEC, 1994.

SILVA, Willian Ribeiro da. Centralidade e produção de loteamentos fechados na cidade de Londrina/PR. In: Cidades médias: Produção do espaço/ Eliseu Savério Spósito, Maria Encarnação Beltrão Spósito, Oscar Sobarzo (org.). 1 ${ }^{\text {a }}$. ed. São Paulo: Expressão Popular, 2007.

SOARES, Beatriz Ribeiro. Cidades Médias: uma revisão bibliográfica. In: ALVES, A . F.; Flávio, L. C.; SANTOS, R. A dos (Org.). Espaço e Território: interpretações e perspectivas do desenvolvimento. $1^{\text {a }}$. ed. Francisco Beltrão, Paraná, 2005. v · p.273.286.

Repensando as cidades médias brasileiras no contexto da globalização. Presidente Prudente (SP): Pós-Graduação em Geografia - FCTUNESP, n. 6, 1999, p. 55-63.

SOBARZO, Oscar. A Produção do Espaço Público em Presidente Prudente: Reflexões na Perspectiva dos Loteamentos Fechados. In: Cidades médias: Produção do espaço/ Eliseu Savério Spósito, Maria Encarnação Beltrão Spósito, Oscar Sobarzo (organizadores). 1ª . ed. São Paulo: Expressão Popular, 2007. 376 p.

SOBARZO, Oscar. Os condôminos horizontais em Presidente Prudente. In: Textos e contextos para a leitura geográfica de uma cidade média/ Maria Encarnação Beltrão Sposito; org. - Residente Prudente: [S.N.], 2001. ISBN: 85- 902133-1-5.

SPÓSITO, Maria Encarnação Beltrão. Loteamentos Fechados em Cidades Médias Paulistas, Brasil: As Especificidades dos Loteamentos Fechados Em Cidades de Porte Médio. In Cidades médias: Produção do espaço/ Eliseu Savério Spósito, Maria Encarnação Beltrão Spósito, Oscar Sobarzo. (orgs.). 1ª ed. São Paulo: Expressão Popular, 2007.

Loteamentos Fechados em Cidades Médias Paulistas, Brasil: Novos Habitats Urbanos. In: Cidades médias: Produção do espaço/ Eliseu Savério Spósito, Maria Encarnação Beltrão Spósito, Oscar Sobarzo (orgs.) 1 ed. São Paulo: Expressão Popular, 2007. 376 p. 
SPOSITO, Maria Encarnação B. As cidades médias e os contextos econômicos contemporâneos. In: SPOSITO, Maria Encarnação B. (org.). Urbanização e cidades: perspectivas geográficas. Presidente Prudente: Unesp, 2001, p. 609-643.

TOWS, Ricardo Luiz; MENDES, César Miranda O estudo da verticalização urbana como objeto da geografia: enfoques e perspectivas metodológicas. In: I Simpósio de Estudos Urbanos/. SEURB: Desenvolvimento Regional e Dinâmica Ambiental. Campo Mourão/PR. Universidade Estadual do Paraná/UNESPAR, 29 a 31 de Agosto de 2011.

WHITACKER, Arthur Magon. Inovações Tecnológicas, Mudanças nos Padrões Locacionais e na Configuração da Centralidade em Cidades Médias. Anais do X Coloquio Internacional de Geocrítica: Los del Problemas Mundo Actual. $\begin{array}{lllll}\text { Soluciones } & Y & \text { Alternativas la Geografía }\end{array}$ Y las Ciencias Sociales. Porto Alegre, 28 de mayo - 1 de junio de 2007. Universidade Federal do Rio Grande do Sul.

Sites Consultados

http: Ilwww.fjp.gov.br

http: Iwww.ibgecidades.gov.br

http: Iwww.ipea.gov.br

http: Iwww.montesclaros.mg.gov.br

Artigo recebido para publicação em jan/14

Artigo aceito para publicação em maio/14 